\title{
Initial assessment of whiplash patients
}

\author{
Dr. R. Gunzburg, MD. PhD./ M. Szpalski/ J. Van Goethem*
}

A ccording to the Q uebec Task Force (28), whiplash is an acceleration-deceleration mechanism of energy transfer to the neck. It may result from rear-end or side-impact motorvehicle collisions, but can also occur during diving or other mishaps. The impact may result in bony or soft-tissue injuries (whiplash injury), which in turn may lead to a variety of clinical manifestations, referred to as whiplash associated disorders (WA Ds).

The frequency of WA D s varies from country to country and region to region (e.g. Saskatchewan). WA Ds may also develop some time after the event, as patients may not report to emergency units immediately or leave the area of the accident through which they happened to travel. According to BARANCIC (1), the female to male ratio is 1:5.

$\mathrm{O}$ the influence of seat belt wearing there are contradictory reports. TUNBRIDGE (31) observed a two-fold increase after introduction of their compulsory use in Scotland, while SA LMI et AL.(26) and Versteegen et AL.(34) found no difference in France and the $\mathrm{N}$ etherlands, respectively.

More recently, dynamic headrests have been introduced (Volvo, Saab, Renault etc), yet their effects on the epidemiology of WA Ds are still unknown.

In the long term, the incidence of neck pain is not different in WA D patients from the non-injured population. Yet, insurance claims are known to have a negative effect on the recovery rate after an accident. True malingering, however, is rare and chronic WA $D$ patients are not cured by a verdict.

$C$ onsequences of injury such as persisting pain, sleep disturbances, litigation etc, may induce secondary psychological factors that in turn participate in the chronicity of the symptoms while creating distress and illness behaviour (BENOIST [3]). Psychological symptoms in posttraumatic conditions are not the cause but rather the consequence of somatic symptoms (RADANOV $[23,24]$ ).

That the outcome of treatment strongly depends on the initial medical care is obvious for severe trauma. This has now also been generally accepted for WADs, underlining the importance of a proper initial assessment in all cases of even less severe trauma.

The general rules concerning the initial assessment of major trauma at the accident scene consist of ascertaining the level of consciousness, the ability to move and the establishment of pain localization and evaluation of associated injuries. In this topic it is important to bear in mind that $10 \%$ of spine fractures are multilevel.
The initial treatment of major trauma at the accident scene comprises the preservation of life (oxygen/shock etc), the prevention of further damage to spine and cord (careful intubation) and the preservation of spinal function (M ethylprednisolone - US NA SCIS II / U S N ational A cute Spinal C ord Injury Study) (7). Instability of the spine must be assumed until the contrary has been proven. O nce the victim has been transferred to an emergency room, new priorities arise: vital functions must be maintained, soft-tissue injuries and acute traumatic central cord syndrome (ATCCS) must be excluded and skeletal radiographs have to be taken ( $C$-spine: A P/lateral/odontoid).

A cute traumatic central cord syndrome (ATCCS) is a complex spinal cord syndrome presenting with incomplete neurological deficits: motor impairment predominates in upper extremities (can walk, cannot move hands), diffuse sensory loss (burning hands) and bladder dysfunction (retention). M RI shows generally involvement of the white matter without haemorrhage. It is thought to be caused by severe cervical hyperextension injuries with squeezing of the spinal cord in a spinal canal narrowed by bulging flava and bony (Fig. 1). The prognosis is generally good with progressive resolution of symptoms (17).

If the initial radiographs show a fracture, further treatment is obviously required (traction, surgery etc). If, however, the radiographs are normal in an otherwise conscious patient without neurologic deficit but presenting with major pain, pillar and oblique views must be taken as well as swimmer's views for distal C-spine and a CT-scan if radiographs are inadequate or insufficient (25).

If the images using these techniques also remain normal, then a hard collar is applied and flexion/extension views and M RI scans are taken within 24-48 hours in order to rule out ligamentous injury. Dynamic M RI scans are not routinely possible, but this may become a standard procedure with time.

There are pitfalls when examining cervical radiographs. On A P open-mouth views, superposition of maxillary incisors on dens may create vertical lucency over the dens (Fig. 2). This must not be mistaken for a vertical schisis (Fig. 3). A Iso, super position of the posterior arch of $\mathrm{C} 1$ on the dens may simulate a horizontal dens fracture or an os odontoideum (Fig. 4).

On neutral lateral films, the atlas-dens axis distance is maximum $3 \mathrm{~mm}$, yet in flexion or in children this can be more. The dens usually extends vertically from the body of C 2 . It may, however, incline backwards as much as $30^{\circ}$ to $40^{\circ}$ and still be

*N iellonstraat 14, 2600, Berchem, B elgium 


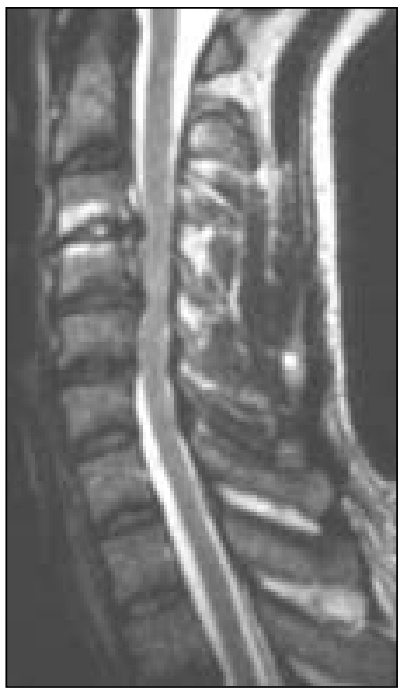

Figure 1

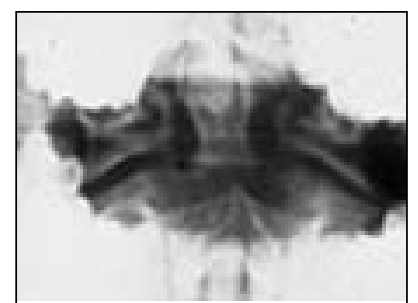

Figure 2

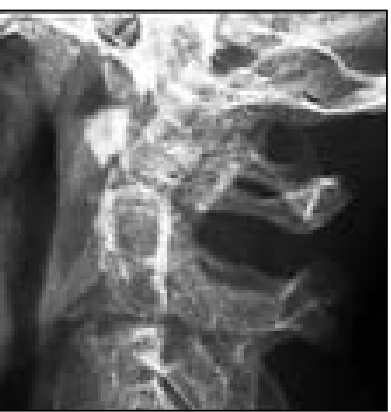

Figure 5

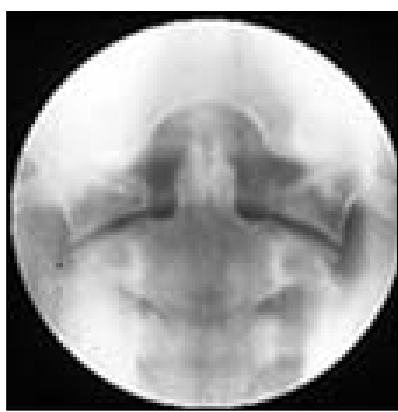

Figure 3

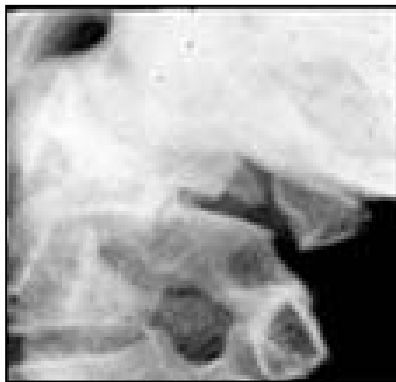

Figure6

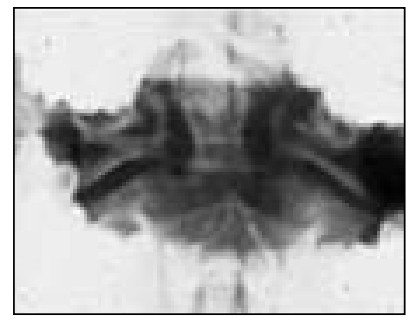

Figure 4

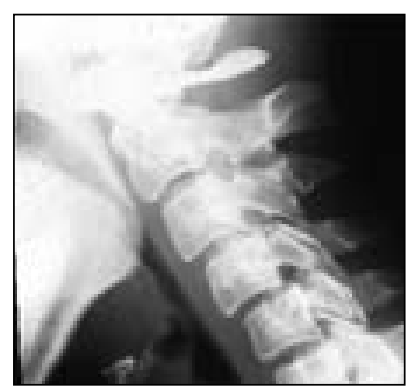

Figure 7

normal (Fig. 5). H ypoplasia or aplasia of the posterior arch of $\mathrm{C} 1$ is not uncommon and has to be differentiated from fractures (Fig. 6).

On lateral view, the internal cortical bone at the base of the spinous processes forms the spinolaminar line. From C 3 downward, the interspinous distance is mostly constant even if the size and shape of the spinous processes may vary. A nterior translation (especially in flexion) of the vertebral bodies is gradual and should not exceed $4 \mathrm{~mm}$ (Fig. 7).

CT or MRI scans are made in the supine position and do not give any information concerning posture.

The initial assessment of WA D is essential, as patients presenting with neck pain on palpation, muscle pain, headache, pain or numbness radiating from neck to arms, hands or shoulders are expected to have a longer course of recovery and should therefore be targeted for early intervention (29).

Once major injury has been excluded and the diagnosis of WA D been established, the initial treatment of WAD in the emergency room can be started. There are four key points to remember:

- Reassure patient about evolution

- No soft-collar

- NSAID

- Early mobilisation

Depending on the local set-up, initial orientation of WA D patients from the emergency room can be an orthopaedic outpatient department (OPD), a trauma OPD, a general practitioner or a multidisciplinary team. During the first follow-up visit, further reassurance and 'whiplash' demystifying must be undertaken. A personal and family history, as well as a detailed accident history, must be made, taking into account the possi-

ble medico-legal implications of WA D.

Personal history is very important, as the very first contact with a physician after injury might reveal anamnestic data related to previous history of headache or neck pain, which might later be unconsciously suppressed in the light of the new symptoms (27). Pre-existing headache and older age are predictors of unfavourable outcome (22).

During an early follow-up visit, it is very important to take an in depth personal history including a psychological assessment such as Minnesota Multiphasic Personality Inventory (MMPI) in order to exclude psychopathology. This personal history must be complemented with a detailed personal accident history: Was the accident anticipated? W as the subject standing still? Or was the subject moving? A nd at what speed? Was the accident with a rear-end, front-end or side impact? Did the subject wear a seat belt? Was there a head restraint? W hich type? W hat was the position of the head at moment of impact?

$70 \%$ of injured patients report immediate occurrence of symptoms: cervical pain, painful spine rotation, shoulder pain, lumbar pain, disturbance of consciousness, diziness. Clinical examination may show upper limb paraesthesia and muscle weakness, neck stiffness and painful and restricted rotation of the head. A t a later stage, visual disturbances, fatigability, concentration impairment, sleep disturbances, irritability or anxiety-depression may be reported. When evaluating these patients it is important, however, to bear in mind that the incidence of chronic neck syndrome in the overall population has been reported from $9.5 \%$ to $34.4 \%(6,14)$ and that no significant difference in chronic symptoms was found at three years between whiplash accident victims and controls in control cohort study (27). 0 ther studies found that between $14 \%$ and $42 \%$ of WA D patients develop chronic neck pain of which $10 \%$ is severe neck pain ${ }^{2}$. 


$\begin{aligned} & \text { Quebec Task Force WAD classification according to } \\
& \text { clinical presentation: }\end{aligned}$
\begin{tabular}{ll} 
Grade & Clinical presentation \\
\hline 0 & No neck complaints \& no physical sign(s) \\
I & Neck pain, stiffness or tenderness \& no physical sign(s) \\
II & Neck complaint \& musculoskeletal sign(s) \\
III & Neck complaint \& neurologic sign(s) \\
IV & Neck complaints \& fracture or dislocation
\end{tabular}

A s for every medical condition, there has to be a consistent message towards the patient. The initial emergency room statements and treatment should be repeated and conformed with reassurance about the evolution of the condition, with most cases recovering within a few weeks to a few months (3). There is no place for soft collars in the treatment of WA D (28).

Some specialised approaches to WAD need to be mentioned: cognitive behavioural training appears to have promising results (32), the usefulness of manipulation is not proven (16), and there are no valid studies supporting the use of epidural or intrathecal medication. BARNSLEY ET AL. (2) found that intra-articular steroids were not effective. Yet, BogDUK (4) used intra-articular local anaesthetic and percutaneous neurotomy to show that zygapophyseal joint pain is the single most common basis for chronic neck pain after whiplash. Subcutaneous sterile water injections at trigger points have been reported to be effective but painful (8).

The useful ness of early administration of nonsteroidal antiinflammatory drugs (NSAIDS) in WAD has clearly been shown by SZPA LSKI ET AL (30) in a randomised, double-blind parallel group study. A $n$ early N SA ID treatment in whiplash hel ps the patient move with less pain, en abling earlier and easier mobilisation. This is important, taken into account that an early activation program improves long term outcome $(15,18)$. Besides, early suffering and impairment of function may affect the later feeling of sickness behaviour. In a prospective, randomised, double-blind study, PetTersson and TOOLA nen (21) found that high-dose methylprednisolone prevents extensive sick leave after whiplash injury.

\section{REFERENCES}

1. BARANCIK JL, KRAmer CF, ThOde HC. Epidemiology of motor vehicle injuries in Suffolk County $\mathrm{N}$ ew York before enactment of the N ew York State seat belt use law. W ashington, DC: U.S. Department of transportation, N ational H ighway Traffic Safety A dministration, June 1989; DOT HS 807: 638

2. BARNSLEY L, LORD S, BOGDUK N. W hiplash injury. Pain 1994; 58:283-307

3. BEN OIST M. N atural evolution and resolution of the cervical whiplash syndrome. In: W hiplash Injuries/C urrent concepts in prevention, diagnosis and treatment of the cervical whiplash syndrome. Edited by GUNZBURG R \& SZPA LSKI M , 1998: pp. 7-128.

4. BOGDUK N. Cervical zygapophyseal joint pain and percutaneous neurotomy: an update to the $\mathrm{Q}$ uébec task force report on whiplash associated disorders. In: W hiplash Injuries/C urrent concepts in prevention, diagnosis and treatment of the cervical whiplash syndrome. Edited by GUNZBURG R \& SZPA LSKI M, 1998: pp. 211 222.

5. Borchgrevink GE, KaAsa A, McDonagh D. et al. A cute treatment of whiplash neck sprain injuries. A randomized trial of treatment during the first 14 days after a car accident. Spine 1998 23:25-31.
There is sufficient evidence indicating that rest and a cervical collar have a detrimental effect in the early management of WA D $(5,15,18,28)$. There is sufficient clinical, epidemiological and biomechanical support for early mobilisation in WA D (20).

Electrophysiological exploration in the assessment of WA D is not commonly used. Yet, Nederhand ET AL.(19) showed that trapezius muscle surface EM G (decreased ability to relax) can distinguish WA D G rade II from healthy subjects. KLEIN ET AL.(12), on the other hand, found WAD patients appeared unable or un willing to rotate the head to the point where SCM muscle activity rises steeply on surface EM G as in healthy subjects (elastic zone). For them, pain or fear of pain keeps WA D patients in the 'neutral zone'. Little is known of sensory and motor evoked potentials in WA D patients (10).

Range of movement is a useful tool to measure cervical spine impairment in WA D. It must, however, be related to age (12). $N$ ot only range of movement out of neutral position, but also rotation out of flexion and extension has to be examined to assess function of the upper and lower C-spine separately (11). Proprioceptive exploration demonstrates that WAD patients may have an inaccurate perception of head position (deficit in ability to reproduce target position of the neck)(13).

0 ther more sophisticated examining techniques address eye movement disorders. VAN NECHEL (33), examined 50 WAD patients referred to a neuro-ophtalmological unit and found that near-sight, pursuit, saccade and accuracy impairments were long-drawn-out deficits after a whiplash injury. A ccording to this author, attention dysfunction and hemispheric arousal deficits probably explain these impairments. $\mathrm{N}$ eurolinguistic and attention disorders in WA D may include word finding difficulties, pseudo-stuttering, dyslexic type sequence errors and inability to express elaborate thoughts, auditory filtering inefficiency (cocktail-party effect) as well as reading and writing difficulties (9). Classic neurolinguistic and neuropsychological tests are not helpful in these WA D cases, as the source of the disorder is located at a general attention level. Therefore, attention evaluation tests (AET) such as the ocular motility test, appear hel pful in WA D.

6. Bovim G, Schrader H, SANd T. Neck pain in the general population. Spine 1994; 19:1307-1309.

7. Bracken MD, Shephard MJ, Collins W F, et al. $M$ ethylprednisolone or naloxone treatment after acute spinal cord injury: one year follow-up data. Results of the second $\mathrm{N}$ ational A cute Spinal Cord Injury Study. J N eurosurg 1992; 76:23-31.

8. Byrn C, O LSSON I, Fa LKheden L, ET al. Subcutaneous sterile water injections for chronic neck and shoulder pain following whiplash injuries. Lancet 1993; 341:449-52.

9. De HeERING A. The whiplash syndrome: neurolinguistic attention disorders. In: W hiplash Injuries/C urrent concepts in prevention, diagnosis and treatment of the cervical whiplash syndrome. Edited by GUNZBURG R \& SZPA LSKI M, 1998: pp. 143-150.

10. DVORAK J. Soft-tissue injuries of the cervical spine (whiplash injuries): classification and diagnosis. In: W hiplash Injuries/C urrent concepts in prevention, diagnosis and treatment of the cervical whiplash syndrome. Edited by GUnZBURG R \& SZPA LSKI M , 1998: pp. 53-60.

11. Dvorak J, Dvorak V, Schneider W et al. Edts. Manuelle medizin:diagnostik. Thieme-Verlag, 1997.

12. Klein GN, Mannion A F, Panjabi M M, Dvorak J. Trapped in the 
neutral zone: another symptom of whiplash-associated disorder. Eur Spine J; 10:141-8.

13. LoUdOn JK, Ruhl M, Field E. A bility to reproduce head position after whiplash injury. Spine 1997; 22:865-8.

14. Makela M, Heliovaara M, Sievers K, et al. Prevalence, determinants, and consequences of chronic neck pain in Finland. A m J Epidemiol 1991; 134:1356-67.

15. MCKINNEY LA. Early mobilisation and outcome in acute sprains of the neck. BMJ 1989; 299:1006-8.

16. MAIGNE J.-Y. W hiplash and spinal manipulation. In: W hiplash Injuries/C urrent concepts in prevention, diagnosis and treatment of the cervical whiplash syndrome. Edited by GUNZBURG R \& SZPA LSKI M , 1998: pp. 193-198.

17. MARTIN DH. The acute traumatic central cord syndrome. In: W hiplash Injuries/C urrent concepts in prevention, diagnosis and treatment of the cervical whiplash syndrome. Edited by G U NZBURG R \& SZPA LSKI M, 1998; pp. 29-134.

18. Mealy K, Brennan H, Fenelon GC. Early mobilization of acute whiplash injuries. Br M ed J (Clin Res Ed) 1986; 292:656-7.

19. Nederhand MJ, IJzerman MJ, Hermens HJ et al. Cervical muscle dysfunction in the chronic whiplash associated disorder grade II (WA D-II). Spine 2000; 25:1938-43.

20. N ORDIN M. Education and return to work. In: W hiplash Injuries/C urrent concepts in prevention, diagnosis and treatment of the cervical whiplash syndrome. Edited by GUNZBURG R \& SZPA LSKI M, 1998: pp. 199-210.

21. Pettersson K, Toolanen G. High-dose methylprednisolone prevents extensive sick leave after whiplash injury. A prospective, randomized, double-blind study. Spine 1998; 23:984-9.

22. Radanov BP, Sturzenegger M, Di Stefano G, et al. Factors influencing recovery from headache after common whiplash. BM J 1993; 307:652-5.

23. Radanov BP, Sturzenegger M, Di Stefano G, Schnidrig A. Relationship between early somatic, radiological, cognitive and psychological findings and outcome during one-year follow-up in 117 patients suffering from common whiplash. $\mathrm{Br}$ J R heumatol 1994, 33:442-448.

24. Radanov BP, Begré S, Sturzenegger S, Augustiny KF. Course of psychological variables in whiplash injury. In: W hiplash
Injuries/C urrent concepts in prevention, diagnosis and treatment of the cervical whiplash syndrome. Edited by G UnZBURG R \& SZPA LSKI M, 1998: pp. 51-160.

25. Ross SE, Schwa B CW, David ET, Delong W G, Born CT. Clearing the cervical spine: initial radiologic evaluation. J Trauma. 1987; 9:1055-60.

26. Salmi LR, Thomas H, Fabry JJ, GIRARd R. The effect of the 1979 French seat-belt law on the nature and severity of injuries to frontseat occupants. A ccid A nal Prev 1989; 21:589-594.

27. Schrader H, Obelieniene D, Bovim G, et al. N atural evolution of late whiplash syndrome outside the medicolegal context. Lancet 1996; 347:1207-11.

28. Spitzer W O, Skovron ML, Salmi LR, et al. Scientific monograph of the Q uébec Task Force on W hiplash A ssociated Disorders: redefining whiplash and its management. Spine 1995, 20:1S-73S.

29. SUisSa S, HaRder S, Veilleux M. The relation between initial symptoms and signs and the prognosis of whiplash. Eur Spine J. 2001; 10:44-9.

30. SzPa LSki M, Gunzburg R, Soeur M et al. Pharmacological interventions in whiplash associated disorders. In: W hiplash Injuries/C urrent concepts in prevention, diagnosis and treatment of the cervical whiplash syndrome. Edited by G UnZBURG R \& SZPA LSKI M , 1998: pp. 175-182.

31. TUNBRIDGE RJ. The long-term effect of seat belt legislation on road user injury patterns. Crowthorne, UK: Transport and Road Research Laboratory, 1989. Research report N o. 239.

32. Van A kKerveeken PF, Vendrig A A. Chronic symptoms after whiplash: a cognitive behavioural. In: W hiplash Injuries/C urrent concepts in prevention, diagnosis and treatment of the cervical whiplash syndrome. Edited by GUNZBURG R \& SZPA LSKI M, 1998: pp. 183-192.

33. Van Nechel C, Soeur M, Cordonnier M, Zanen A. Eye movement disorders after whiplash injury. In: W hiplash Injuries/Current concepts in prevention, diagnosis and treatment of the cervical whiplash syndrome. Edited by GunZBURG R \& SzPA LSKI M, 1998: pp. 135-141.

34. Versteegen GJ, Kingma J, Meijler W J, ten Duis HJ. Neck sprain in patients injured in car accidents: a retrospective study covering the period 1970-1994. Eur Spine J 1998; 7:195-200.

This material was presented at the International C ongress on W hiplash A ssociated Disorders, Berne, Switzerland, M arch 8 to 10, 2001. The paper appeared originally in the book "W hiplash A ssociated D isorders" - medical, biomechanical and legal aspects, published by Staempfli Publishers Ltd, Berne 2002. The paper is published in N orth A merica in Pain Research \& M anagement with the permission of Staempfli Publishers Ltd. 


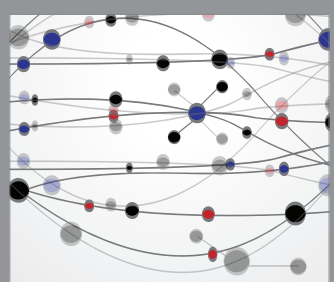

The Scientific World Journal
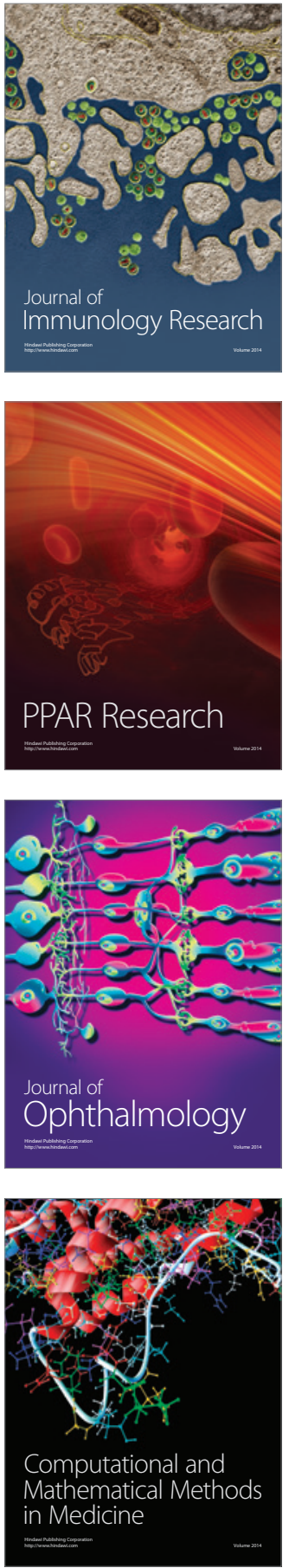

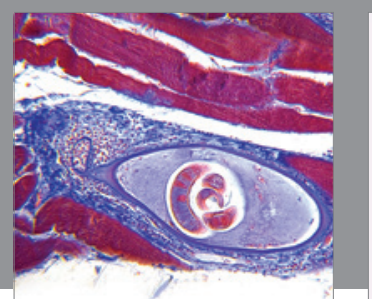

Gastroenterology Research and Practice

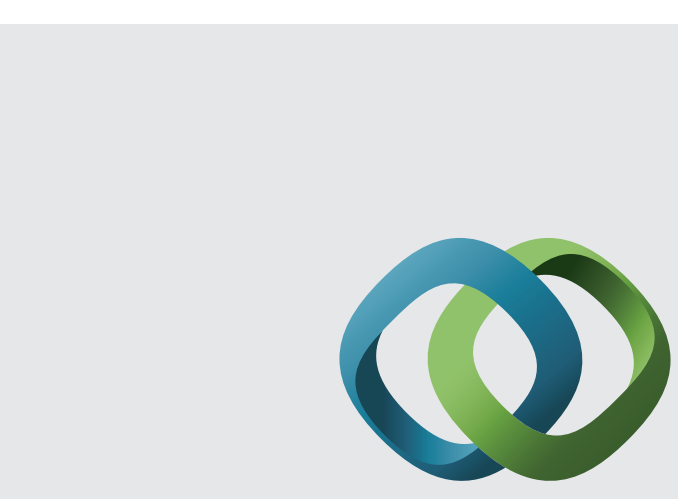

\section{Hindawi}

Submit your manuscripts at

http://www.hindawi.com
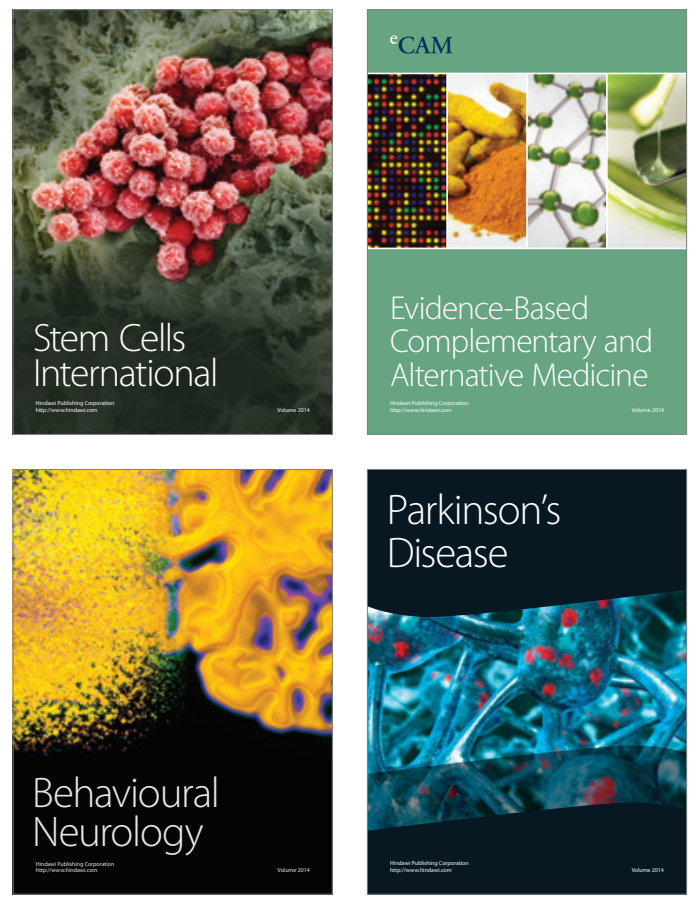
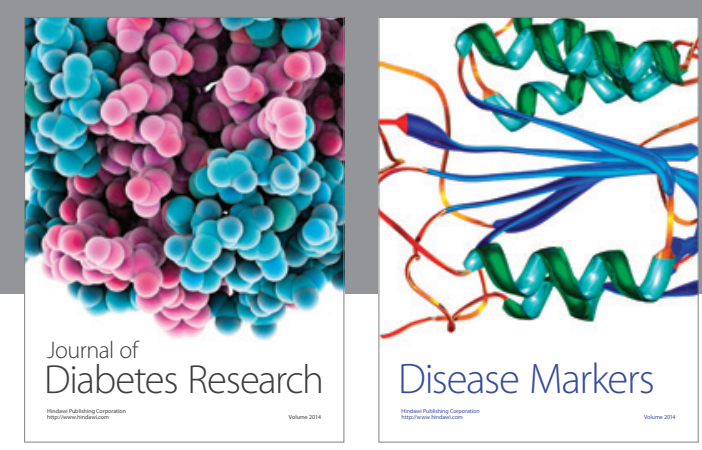

Disease Markers
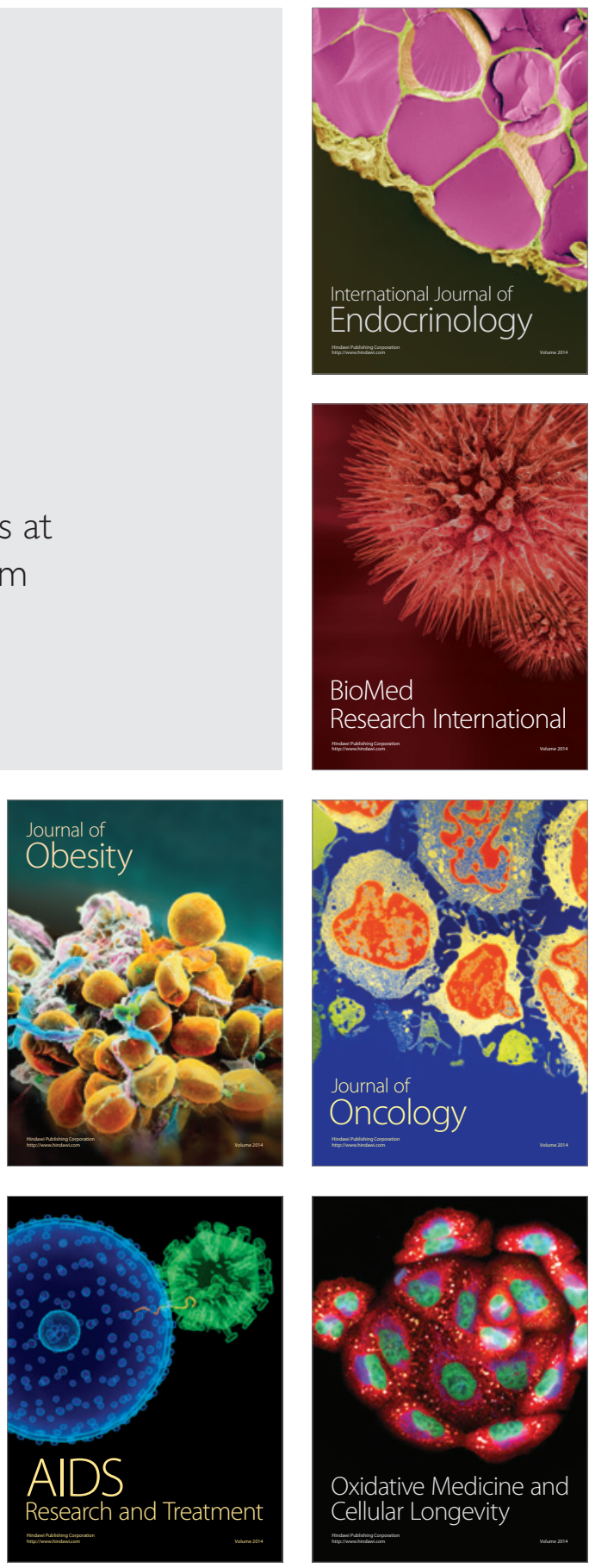